УДК 821.161 .1

DOI: 10.21779/2542-0313- 2017-32-2-62-68

\title{
С.М. Гумбаталиева
}

\section{Средства выразительности в обращениях в Коране}

Бакинский государственный университет; Азербайджан, AZ1148, Баку, ул. 3. Халилова, 23; nasrullahbdu@mail.ru

В статье рассмотрены особенности обращения в Коране с точки зрения выразительности. Среди многих исследований Корана, возможно, ведущее место принадлежит его стилистике. Это связано с тем, что данная книга ниспослана Богом, и потому она имеет своеобразный стиль. В этом отношении привлекают две особенности его стиля, которые отличаются от всех известных до сих пор. Представители арабского языкознания обращение относили к средствам выразительности, рассматривая особенности этой части речи в разделе стилистики. Отмечается, что в арабском языке есть многочисленные примеры обращений в качестве вспомогательных частей речи (адатов). Несмотря на это в Коране предпочтение отдается адатам типа «йе» или «аййуха», что связано с возможностями их выразительности. Несомненно влияние стилистики Корана на дальнейшее развитие наречий и диалектов, а также самого литературного арабского языка. В Коране достаточно обширно применяются хитабы (обращения). Они используются как с адатами, так и без них. Отдельные аяты Корана и 12 сур также начинаются с хитаба. В Коране хитабы есть в четырехстах семидесяти девяти аятах. Хитабы в Коране обращены не только к пророку Мухаммеду (c), но и от пророка Мухаммеда (c) - к другим людям, или же просто есть обращения к другим лицам. В этих обращениях в большинстве случаев или высказывается какое-либо повеление, или же высказывается какой-либо запрет.

Ключевые слова: Коран, выразительность, красноречие, обращение, вспомогательные части речи.

Арабы, чей язык выделяется среди других языков народов мира своей выразительностью и красноречием, высоко ценят слово Божье, заключенное в Коране: попав под очарование богатства смыслов этого божественного текста, они поняли, что он стоит намного выше, чем доисламская поэтическая мысль, и вплотную занялись исследованием текста Корана. Прежде всего следует подчеркнуть, что ученых, занимающихся стилистикой, привлекли вопросы выразительности и красноречия этой божественной книги. Они стали стремиться изучать различные смыслы коранического текста. Кроме того, это способствовало в целом развитию различных отраслей самой стилистики как науки. Изучение текста Корана способствует дальнейшему развитию арабского языка, совершенствованию его стилистических особенностей, выявлению влияния этого языка на другие языки мира, в том числе на азербайджанский язык.

Вопросы стилистики Корана были предметом исследования многих ученых, в том числе таких известных, как Ибн Кутейбе [4], Ахмед Фарис [7, 8], Аль-Мутаннаби [11], Аз-Замахшари [14], Сеййид Кутуб [16], Аль-Алявиййа [17] и др. В России исследование стилистики Корана имеет давние традиции [10, 15, 18 и др.]. Вместе с тем сама стилистика Корана достаточно сложная и потому требует постоянной смены точек зрения и подходов в своем исследовании.

Основные средства выражения красноречия. Рассмотрим основные средства выражения красноречия: 
1) использование приказа, просьбы, требования, пожелания, вопроса, запрета и других действий усиливает степень выразительности обращения, показывая его возможности;

2) многообразие обращений не является случайным, здесь есть моменты касающиеся выразительности. Каждый из адатов (обращений) нетолько содержит смысл, связанный с выразительностью, но и одновременно обладает языковыми и функциональными свойствами. Несомненно, что подобные качества дают возможность исследовать обращения с точки зрения общения и выразительности.

3) обращение приобретает помимо основного смысла еще и различные выразительные оттенки, поэтому применяется именно в указанном варианте и, таким образом, превращается в объект исследования стилистики;

4) обращения, используемые в Коране, обычно бывают связаны с одним из вышеуказанных моментов; в итоге они становятся объектом исследования (как одной из сфер стилистики) ученых-языковедов;

5) при рассмотрении стихов и хутб (речей-проповедей) в период Джахилиййа (доисламский период) и в дальнейшем становится ясно, что труженики пера указанного периода в своем творчестве использовали обращения в широком смысле, в том числе и в качестве средства выразительности.

О числе адатов-обращений. Ученые Средневековья всесторонне исследовали вопросы обращения, уточняя адаты, которые там применялись, давая определение этому термину в рамках стилистики как науки [10, с. 171]. Известные арабские ученые, изучающие стилистику арабского языка, в связи с этим писали: «Обращение есть призыв говорящего, посредством использования адатов обращения, заменяющих глагол “أدادي", сأدعو، средство привлечения внимания противоположной стороны [3, с. $125 ; 9$, с. $113 ; 7$, с. 180]. Исследователи при этом подчеркивают, что обращение обычно соответствует тем адатам, с помощью которых они создаются (т. е. устный призыв с помощью адата), отмечая, что при внятном тексте они могут и выпадать $[17$, т. 3 , с. 296]. Например:

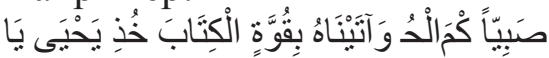

“(И когда Йахья подрос, Аллах Всевышний повелел ему): «О, Йахья! Держись Писания [Торы] сильно [знай его содержание, понимай его смысл и поступай по нему]!» И даровали Мы ему [Йахье] мудрость, когда он был (еще) мальчиком (Марьям: 12)

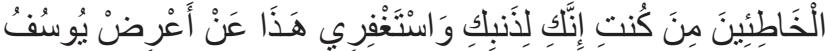

“Йусуф [Иосиф], забудь об этом! А ты проси прощения за свое прегрешение, ибо ты совершила грех»” (Юсуф: 29).

Ученые, изучающие стилистику, определили число обращений-адатов, их восесь - гамза, эй, йаа, айаа, хайаа, аа, аай, ваа.

Адаты - обращения применяются в языке следующим способом:

1) «гамза» и «эй» используются при обращении к кому-либо, стоящему поблизости, например:

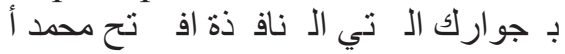

«Эй, Мухаммед, открой окно рядом с тобой».

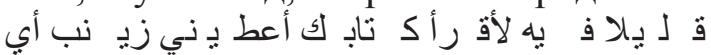

«Эй, Зейнаб, дай мне книгу, я немного почитаю».

2) остальные же шесть адатов применяются при обращении к лицам, находящимся поодаль, например:

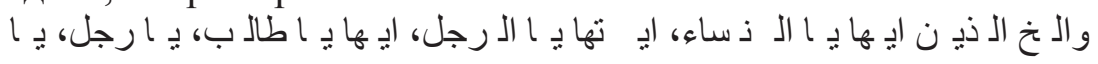


«Эй, мужчина; эй, студент; эй, мужчины; эй, женщины; эй, те, кто...» и т. д.

По мнению Ибн Гаджиби, адат «йа» практически используется как для близких, так и дальних расстояний, поскольку это есть средство привлечения внимания в абсолютном смысле [2, т. 1, с. 131]. По мнению Замахшари, этот адат на самом деле должен использоваться при разговоре на дальнем расстоянии. Дело в том, что использование на близком расстоянии может быть лишь в случае, если необходимо подчеркнуть, что собеседник по своему положению выше обращающегося, или же он привлекает внимание своим величием и размахом деятельности, например: اله بـ - О (ай), боже! [14, с. 35].

В некоторых случаях, в зависимости от стиля говорящего, создается впечатление, что обращающийся находится рядом, и поэтому в указанном положении предпочитаются адаты «гамза» или «ай». Таким образом выражается духовная или нравственная близость говорящего к противоположной стороне [4, т. 3, с. 58].

Как известно, обращение может иметь такие смыслы, как приказ, запрет, вопрос, пожелание и другие. Как уже отмечалось выше, Сибавейхи и большинство ученых из Басры считают, что адат на самом деле заменяет глаголы “"أدعو". Именно по- или "ادي". этому это предложение превращается в предложение-сказуемое. Отметим также, что между арабскими языковедами нет единого мнения о том, к какой части речи следует отнести обращение. Некоторые из филологов считают, что практически адаты заменяют вышеуказанные глаголы, некоторые же - именное сказуемое или же являются адатом внимания [12, т. 1, с. 303]. Есть также мнение, что обращения имеют право на самостоятельное существование [6, с. 15].

Что же касается исследователей красноречия, то, хотя они в подобном подходе к адатам обращения и отдают предпочтение глаголу, фактически стремятся исследовать глагол и такие смыслы, как повеление, запрет, вопрос, пожелание во взаимном обмене. Дело в том, что каждое из них может использоваться взамен другого. Не учитывая смыслы этих форм, исследователи останавливаются на одной из модальных форм,

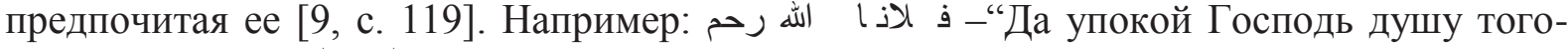

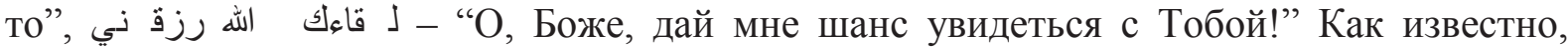
предложения подобного рода в арабском языке формально называются отглагольными предложениями и подчиняются законам утверждения или отрицания в грамматике. Если посмотреть на возможности использования этих предложений, то мы увидим их в следующей форме:

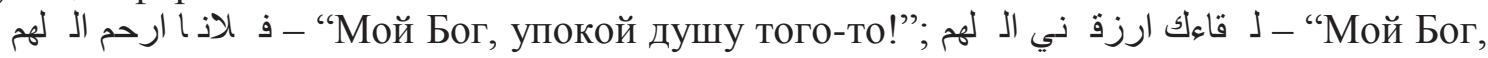
дай шанс мне увидеться с Тобою!”

В зависимости от того, каким является приглашение в обращении - явным или скрытным, оно всегда связано с выразительностью речи. Именно эта особенность обращения привлекает внимание исследователей. В частности, можно отметить следующее:

1) в зависимости от того, используется ли это выражение в диалоге или в иных целях, здесь все равно предполагается взаимная связанность внутри него;

2) в обращении или призыве говорящего к противоположной стороне пробуждаются интерес и внимание к конкретной теме;

3) вторая сторона (к которой обращаются) сосредоточивает свое внимание на конкретной теме, о которой идет речь;

4) здесь наблюдается стремление к сокращению числа слов и тем самым - уменьшению их числа; 
5) у противоположной стороны мысли сосредоточиваются воедино (вокруг темы), тем самым к мыслительному процессу, связанному с выразительностью речи вокруг нее, присоединяется воображения.

Обращение в определенных моментах, выходя за рамки истинного смысла, выражает определенные метафорические смыслы [5, с. 364]. Вот некоторые из них: 1) молитва; 2) побуждение; 3) понукание; 4) глубокие скорбь и сожаление; 5) отвлечение; 6) уточнение; 7) мольба о помощи; 8) удивление; 9) траур; 10) оскорбление; 11) любовь, влечение; 12) восхищение; 13) принуждение; 14) порицание; 15) внимание; 16) удовольствие; 17) восхваление.

При обращении адаты могут оставаться неизменными, при этом в зависимости от состава предложения, в котором они применены (предложение или выражение), и от смысла выразительность значительно меняется; при этом изменение смысла адатов уже не может быть объектом споров, поскольку в зависимости от формы выражения, от стиля выражения изменяется содержание выразительности. Образно говоря, адат похож на изделие из цветного стекла. Поставив его рядом с предметом белого цвета, например, красное рядом с белым или рядом с зеленым, мы будем видеть эти цвета. Здесь все хранит свою самобытность, то есть свои качества и признаки, относящиеся к нему. То же, что меняется, - это результат отражения, цвет в результате этого процесса [9, c. 217].

Что же касается средств выразительности в Коране, то здесь в основном делается упор на описание, что позволяет выявить красноречивость текста [16, с. 195]. Эти описания даются к месту и настолько точны, что при внимательном прочтении этого божественного произведения перед глазами предстает живая картина всего происходящего.

В Коране путем подобного описания и выражений достигнут высокий уровень словесного искусства. Эта Священная книга возвысилась до уровня волшебного искусства, до наивысшей точки выразительности и красноречия.

Следует отметить, что в тексте Корана обращение больше применяется через адат «йа». Этот адат, который больше проявляется в отмечаемых вариантах (аль-мазкур), нежели в неотмечаемых (аль-махзуф), во многих случаях используется совместно с адатом «аййун».

Величественный Небесный Властитель с помощью этих адатов, через обращения которые использованы в Коране, обращает внимание своих подданных на те моменты, о которых они прежде не знали или на которые просто не обращали внимания, или же стремится отвадить их от неправедных дел. Именно поэтому эти обращения, характеризующиеся упорством, настойчивостью, красноречием, откладываются в памяти и сознании людей [13, т. 1, с. 174].

В Коране при рассмотрении способов использования обращения важно классифицировать их по особым рубрикам и отделам. В этой классификации наиболее интересным является рассмотрение возможности метафоричности этих обращений. Учитывая размеры данной статьи, считаем более уместным рассмотрение этих свойств обращения на примере некоторых аятов Корана:

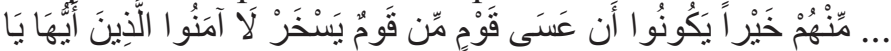

О те, которые уверовали! Пусть одни люди не насмехаются над другими, ведь может быть, что те лучше них ... (Аль-Худжурат: 11).

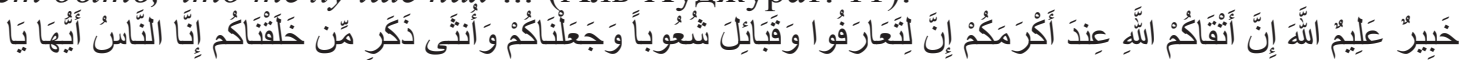

О люди! Воистину, Мы создали вас из мужчины и женщины и сделали вас народами и племенами, чтобы вы узнавали друг друга, и самый почитаемый перед Аллахом 
среди вас - наиболее богобоязненный. Воистину, Аллах - Знающий, Ведающий ... (АльХуджурат: 13).

Если углубиться в смысл вышеуказанных аятов, то можно увидеть, что в первом

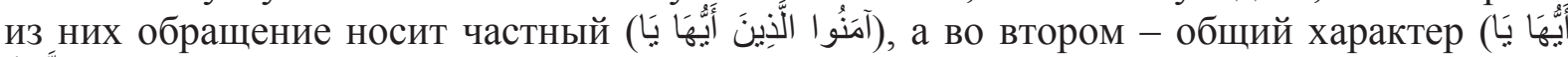
النَّاسُ (النّأ сматриваемый стиль, форма выражения.

Всевышний в первом обращении, считая правоверных как бы единым организмом, предупреждает, что от того, что они будут высмеивать друг друга, относиться друг к другу с издевкой, они не выиграют, поскольку потеряют единство, целостность. Ведь при заболевании в теле какого-либо одного органа все тело начинает терпеть муки. Именно поэтому в подобном обращении есть чувство благодати и милосердия.

Что же касается второго обращения, то здесь чувствуется обстановка единения и целостности. Здесь обращаются не к отдельной группе людей, а именно ко всему человеческому роду. Людям напоминают, что все произошли от первого человека Адама и его жены Евы. Со временем люди были разделены на разные племена и народности по определенной причине и рассеяны в отдельных местах на земле [16, с. 288].

Правила арабского языка, прошедшего до Корана значительный путь развития, его литературные возможности и правила стиля были значительно усилены. Поэты и писатели доарабского периода, который называется периодом Джахилиййа (Невежества), создали на этом языке великолепные образцы культуры.

Следует отметить, что у поэзии есть уникальный язык, основанный на внутренних эмоциях и необычной силы возможностях выражения. Слова в стихах сильно отличаются от прозаических слов и обладают способностью раскрывать свой внутренний смысл поэтическим способом через уникальные образы и изображения [7, с. 28].

Что касается прозы, то она пытается достичь поставленной цели, прибегая больше к разуму и мысли.

Невозможно найти поэта Джахилиййа, который не использует обращение в своем творчестве.

В дополнение к Корану можно обратиться к хадисам пророка Мухаммеда. Когда мы рассматриваем хадис «Вида Хаджи» Пророка, мы видим, что он использует обращение в одной и той же проповеди несколько раз.

Первый призыв здесь в форме «ادب что целью творения является поклонение Богу, Творцу. Согласно исламской мысли и Корану, как джинны, так и люди были созданы, чтобы поклоняться только Богу.

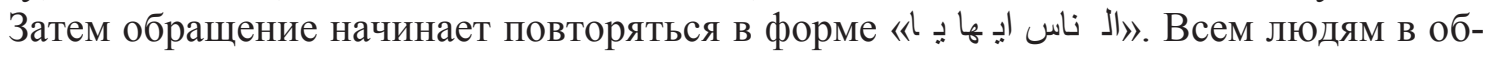
ращении напоминается о греховности некоторых действий, внушаются мысли о необходимости строить искренние и ласковые отношения, что мужчины доминируют над женщинами, но и женщины также имеют права. Таким образом, здесь идет описание обращения Пророка (да благословит его Аллах и приветствует) к своему народу. При внимательном рассмотрении обращения в этой проповеди, мы видим, что используется

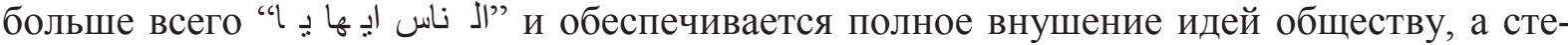
пень выразительности достигает своего высшего уровня.

После ухода Пророка (c) из мира этот стиль его обращения был сохранен, и его последователи, халифы династии Рашиди, обращались к своим гражданам из разных слоев общества, используя ту же форму (ال ناس اي ها يـ الئ в своих проповедях и речах. 


\section{Выводы}

Таким образом, особенности обращения с точки зрения выразительности представляют значительный интерес в Коране, поскольку сам текст Корана сыграл большую роль в развитии и становлении современного арабского языка. Кроме этого, обращения как составная часть грамматики любого современного языка в сравнительном плане также могут принести пользу для изучения вопросов социолингвистики и вопросов становления языковой системы. Данная проблема нуждается в дальнейшем рассмотрении именно в сравнительном плане, а также с точки зрения функционирования различных языковых систем.

\section{Литература}

1. Әbи Әl-Alə Әl-Marri. Şuruhu Saqti Әz-Zəndi. - Ol-Qahiratu, 1946. - 345 с. (на араб.).

2. İbn Hacib. Şərhu Әl-Kəfiyəti. - Beyrut, 2001. - 129 c. (на араб.).

3. Әbdu Әl-Oziz Әtiq. İlmu Әl-Mәani. - Beyrut, 1972. - 298 с. (на араб.).

4. İbn Quteybə. Uyunu Ol-Әxbər. - Beyrut, 1963. - 321 c. (на араб.).

5. Әl-Bəkri Әbu Ubeyd. Faslu Ol-Maqali fi Şərhi Kitəbi Әl-Әmsəl. - Beyrut, 1971. 401 с. (на араб.).

6. Od-Duktur Abduh Or-Racihi. Durusun fi Kutubi On-Nəhvi. - Beyrut, 1954. - 281 c.

7. Ohməd Faris. Ol-Kitabətu va Әt-Təbir. - Beyrut, 1979. - 239 с. (на араб.).

8. Әhmad İbn Faris. Әs-Sahibiyyu. - Beyrut, 1964. - 420 c. (на араб.).

9. Bəkri Әş-Şeyx Әmin. Әl-Bələğətu Ol-Arabiyyətu fi Saubihəə Әl-Cədid. - Beyrut, 1979. - 171 с. (на араб.).

10. Гуськова O.В. Еще раз об арабских знаках препинания как о графических единицах двойного знакового характера // Филологические науки. Вопросы теории и практики. - 2014. - № 2 (32). - С. 74-79.

11. Ol-Mutənəbbi. Divanu Ol-Mutənəbbi. Şərhu Ol-Vahidi. - Beyrut, 2004. - 365 с. (на араб.).

12. Әs-Sirafi. Şərhu Әs-Sirafi. alə Sibəveyhi. - Bəğdəd, 1993. - 412 с. (на арабск.).

13. Әz-Zəməxşəri. Ol-Kəşşəf an Haqaiqi Ot-Tənzil va Uyuni Ol-Aqavil fi Vucuhi ӘtTәviil. - Beyrut, 1318. - 298 с. (на араб.).

14. Әz-Zəməxşəri. Әl-Mufassal, Ol-Qahiratu, 2008. - 322 с. (на араб.).

15. Фролова Л.Н. Лексико-семантические особенности перевода Корана // Вестник Адыгейского государственного университета. Сер. 2: Филология и искусствоведение. - 2009. - № 2. - С. 14-23.

16. Seyyid Qutub. Әt-Tasviru Ol-Fənniyyu fi Ol-Qurani. Beyrut: 1963. - 438 с. (на араб.).

17. Yəhya İbn Həmzə Әl-Әləviyyə. Әt-Tıraz Әl-Mutədammən Li Әsrari Әl-Bəlağəti va Ulumu Haqaiqi Әl-İcəz. - Әl-Qahiratu, 1914. - 455 c. (на арабск.).

18. Эфендиева С.А. Коранические мотивы в поэзии И.А. Бунина // Вестник Московского государственного областного университета. Сер.: Русская филология. - 2011. - № 4. - С. 154-159.

Поступила в редакиию 30 июля 2017 г. 
UDC 821.161.1

DOI: 10.21779/2542-0313- 2017-32-2-62-68

\section{Means of expressiveness in adress in the Quran}

\section{S.M. Gumbatalieva}

Baku State University; Azerbaijan, AZ1148, Baku, Z. Khalilova st., 23; nasrullahbdu@mail.ru

The article reviews the peculiarities of adress in the Quran from the point of view of expressiveness. The representatives of Arabic linguistics referred an adress to the means of expression, considering the peculiarities of this part of speech from the point of view of the stylistics. Among many sciences about the Quran, perhaps the leading place belongs to its stylistics. This is due to the fact that the book is sent down by God, and therefore it has a peculiar style. In this regard, two features of his style are distinguished, which differ from all known so far. It is noted that in Arabic there are numerous examples of addressing someone as auxiliary parts of speech (adats). Despite this, in the Quran preference is given to adats like "ye" or "ayyukha", which are connected with their potential of the expressiveness. The influence of the Quran stylistics on the further development of dialects and accents, as well as the literary Arabic language itself is undeniable. In the Qur'an, hitabs (appeals) are used extensively. They are used both with adats, and without them. In addition to hitabs, individual verses of the Quran and 12 suras also begin with hitab. In general, there are hitabs in the Qur'an in four hundred and seventy-nine verses. Hitabs in the Quran are addressed not only to the Prophet Muhammad (s), but also from the Prophet Muhammad (s) to other people, or simply to other people. In these appeals, in most cases, either a command is made, or some prohibition is expressed.

Keywords: Quran, expressiveness, eloquence, conversion, auxiliary parts of speech.

Received 30 July, 2017 